\title{
Habilidades socioemocionais: da BNCC às salas de aula
}

\author{
Marina Kurotusch Canettieritø \\ Universidade Federal de Goiás, Goiânia, GO, Brasil \\ Jordana de Castro Balduino Paranahybaii \\ Universidade Federal de Goiás, Goiânia, GO, Brasil \\ Soraya Vieira Santosiii \\ Universidade Federal de Goiás, Goiânia, GO, Brasil
}

\begin{abstract}
Resumo
O objetivo deste trabalho é identificar as bases epistemológicas e os marcos legais que sustentam a concepção de habilidades socioemocionais na Base Nacional Comum Curricular destinada ao Ensino Médio. A pesquisa teve caráter documental; durante sua realização, também foram analisados três materiais de educação socioemocional de editoras brasileiras a fim de melhor compreender como o conceito trazido pela Base Nacional Comum Curricular pode comparecer nas atividades escolares. Além do conteúdo explícito, também foi considerado o contexto sociopolítico que perpassa pelas temáticas abordadas por tais materiais. Sabendo que a Base Nacional Comum Curricular busca manter a pluralidade dos currículos e a autonomia das escolas, foram apresentados benefícios e riscos da adoção do conceito aberto sobre habilidades sociais e emocionais e suas possíveis implicações na formação dos educandos e na atuação do professor. Ademais, o trabalho teve por sustentáculo a visão da psicologia escolar crítica, principalmente pelas contribuições das pesquisadoras Patto, Smolka, Lemos e Macedo.
\end{abstract}

\section{Palavras-chave}

Habilidades socioemocionais. BNCC. Ensino Médio. Currículo.

\section{Socioemotional abilities: from BNCC to classrooms}

\begin{abstract}
This study aims to identify the epistemological bases and legal marks that sustain the conception of socioemotional abilities in the Brazilian National Common Curricular Base directed to High School. It is a documental research; during its execution other three materials of socioemotional education by Brazilian publishers were analyzed as well in order to better understand how the concept established by the National Common Curricular Base can be present in school activities. Beyond explicit content, we also considered the social and political context that runs through the themes brought by these materials. Considering that the National Common Curricular Base attempts to maintain the plurality of curricula and school autonomy, the study showed the benefits and risks of adopting an ample conception of social and emotional abilities and its possible implications on students' education and teachers' work. Moreover, the project was grounded on the perspective of critical school psychology, mainly on the contributions of researchers Patto, Smolka, Lemos, and Macedo.
\end{abstract}

\section{Keywords}

Socioemotional abilities. BNCC. High School. Curriculum.

Educ. Form., Fortaleza, v. 6, n. 2, e4406, maio/ago. 2021

DOI: https://doi.org/10.25053/redufor.v6i2.4406

https://revistas.uece.br/index.php/redufor/index 
Habilidades socio-emocionales: de la BNCC a las aulas

\begin{abstract}
Resumen
El objetivo de este trabajo es identificar las bases epistemológicas y los marcos legales que fundamentan la concepción de las habilidades socio-emocionales en la Base Nacional Comum Curricular destinada a la Enseñanza Media. La investigación fue de carácter documental, donde se analizaron tres materiales de educación socio-emocional de editoriales brasileñas para comprender mejor cómo el concepto aportado por la Base Nacional Comum Curricular puede estar presente en las actividades escolares. Además del contenido explícito, también se consideró el contexto sociopolítico que atraviesa los temas tratados en esos materiales. Sabiendo que la Base Nacional Comum Curricular trata de mantener la pluralidad de los planes de estudio y la autonomía de las escuelas, se presentaron los beneficios y riesgos de la adopción del concepto abierto sobre habilidades socio-emocionales y sus posibles repercusiones en la formación de los estudiantes y la actuación del profesor. Además, el trabajo se apoyó en la visión de la psicología escolar crítica, especialmente las contribuciones de las investigadoras Patto, Smolka, Lemos e Macedo.
\end{abstract}

\title{
Palabras clave
}

Habilidades socio-emocionales. BNCC. Educación. Currículo.

\section{Introdução}

A nova Base Nacional Comum Curricular (BNCC) reorganizou o ensino para a promoção de dez competências gerais, que concorrem, no âmbito pedagógico, para o desenvolvimento e aprendizagem dos educandos. Dentre essas competências, têm ganhado destaque as três últimas citadas na introdução da BNCC, que visam à promoção de habilidades sociais e emocionais. A homologação da BNCC se deu em duas datas, sendo o documento destinado à Educação Infantil e ao Ensino Fundamental aprovado em 2017 e o destinado ao Ensino Médio, em dezembro de 2018. Na época da elaboração da BNCC, a etapa do Ensino Médio sofria reformas a partir da Lei no 13.415/2017, que prevê, dentre outras mudanças, o aumento da carga horária, o fomento à implantação de escola de tempo integral para o Ensino Médio e itinerários formativos, a fim de proporcionar aos jovens o papel de protagonistas no aprofundamento de determinadas áreas do conhecimento e na formação técnica. De acordo com dirigentes do Ministério da Educação (MEC), tais alterações visam aproximar a educação escolar da realidade juvenil, conter a evasão escolar, aumentar o número de vagas e reestruturar o currículo aos novos desafios do século XXI.

Educ. Form., Fortaleza, v. 6, n. 2, e4406, maio/ago. 2021

DOI: https://doi.org/10.25053/redufor.v6i2.4406

https://revistas.uece.br/index.php/redufor/index 
Numa análise do escopo político mais amplo, Da Motta e Frigotto (2017) compreendem a urgência de aprovação da Reforma em questão como corrida para o desenvolvimento econômico a partir do investimento em capital humano e tecem suas críticas a respeito de uma formação baseada nos marcos restritos e instáveis das necessidades do mercado. É evidente a preocupação com a transição do mundo escolar para o trabalho, sobretudo tendo em vista o cenário nacional de mudanças substanciais do modo de produção, a baixa permanência de jovens no Ensino Médio, a chegada de uma geração crescente de adolescentes, ao mesmo tempo que o desemprego se torna cada vez mais estrutural.

O vínculo entre os novos currículos e as emergentes demandas do mundo do trabalho é inegável, tanto que a adoção do termo "competência", hoje incorporada aos currículos escolares, remonta à década de 1980, quando a noção de qualificação para o trabalho foi gradualmente sendo substituída pela noção de capacidades subjetivas, que garantiriam a permanência do trabalhador em um mundo de produção flexível e tecnológico (FREIRE, 2009; RAMOS, 2002). A demanda por um "novo profissional" advém de um setor produtivo intelectualizado e de exigências que ultrapassam às dos modelos fordistas e tayloristas. O trabalhador é contratado não só para operar máquinas e gerenciar pessoas, como também para diagnosticar, atualizar, lidar com o coletivo e arcar com as pressões individualmente, incorporando lemas empresariais como se fossem as próprias empresas, sem falar na formação para o desemprego e para a competitividade a fim de servirem ao sistema de produção (FREIRE, 2009; RAMOS, 2002). Neste sentido:

[...] a ênfase recai em aspectos socioemocionais que capacitam as pessoas para buscarem o que desejam, tomarem decisões, estabelecerem objetivos e persistirem no seu alcance mesmo em situações adversas, de modo a serem protagonistas do seu próprio desenvolvimento e de suas comunidades e países. (IAS, 2014, p. 5).

Não é recente a ideia de trabalhar habilidades emocionais no ambiente escolar, no entanto, por ter caráter mandatório, a nova BNCC traz à tona a necessidade de pensar e formular ações educativas cujas atenções sejam voltadas para essas competências. Inúmeros materiais são formulados por editoras brasileiras e internacionais com vistas a ocupar a vanguarda no cumprimento das novas exigências; a

Educ. Form., Fortaleza, v. 6, n. 2, e4406, maio/ago. 2021

DOI: https://doi.org/10.25053/redufor.v6i2.4406

https://revistas.uece.br/index.php/redufor/index 
questão a ser posta é: quais os sentidos e fins pretendidos com a educação socioemocional?

É válido lembrar que historicamente temos herdado uma visão dualista de emoção e cognição, colocando-as em lados opostos e incompatíveis, de maneira que a escola tem sido considerada espaço exclusivo para o desenvolvimento da cognição (LEITE, 2012). Isso porque, consoante Leite (2012), a razão foi eleita como superior e responsável por controlar as emoções, como se estas últimas fossem responsáveis pelos "desequilíbrios" humanos. O autor ainda considera que foi somente no século passado, a partir de novas concepções sociológicas, filosóficas e psicológicas, que a afetividade e a cognição passaram a ser vistas como dimensões indissociáveis, permitindo o avanço de inúmeras teorias sob essa perspectiva.

Contudo, as concepções ultrapassadas perduram à sombra de novas formas. Aceitam-se as emoções como constituintes e sempre presentes no sujeito-educando, mas permanece a ideia de controle e domesticação, antes mesmo de compreender suas características e importância. Patto (2000) há muito denunciou currículos de "alfabetização emocional" por não englobarem reflexões sobre as condições adversas que geram comportamentos indesejados, colocando sobre o sujeito o peso da adaptação inquestionável aos ditames sociais. A autora traça uma série de críticas a respeito das bases liberais nas quais se alicerçam os objetivos de tais programas: os fins últimos são o sucesso pessoal num mundo extremamente competitivo. Até mesmo o senso de cooperação é estimulado com foco nos ganhos individuais.

Por esse viés, Patto (2000) afiança que, no sentido oposto ao que propõem, os currículos de educação socioemocional que não questionam as estruturas sociais e velam as origens da barbárie não passam de meros adestradores que compactuam com o sistema de desigualdade e injustiça. De acordo com a autora, a educação, seja ela de que caráter for, não pode ser mero receituário para a eficiência.

Contribuindo com uma visão crítica, Smolka et al. (2015) analisam as frágeis bases epistemológicas de um projeto de avaliação da personalidade baseada em cinco aptidões socioemocionais. Financiado por instituições reconhecidas, o projeto objetiva fornecer uma política pública a ser adotada em todo o território brasileiro a fim de obter parâmetros acerca das competências socioemocionais e relacioná-las com o sucesso ou o fracasso escolar.

Educ. Form., Fortaleza, v. 6, n. 2, e4406, maio/ago. 2021 
As pesquisadoras principiam o texto expondo que os testes quantitativos e métricos do sistema de avaliação proposto não possuem referencial teórico bem definido, e esse seria o primeiro equívoco do programa. Inexiste consenso sobre o que é e como se forma a personalidade; por esse argumento, Smolka et al. (2015) problematizam a ideia de características desejáveis, com base no que viria a ser uma personalidade ideal. Outra crítica recai severamente sobre o programa por este desconsiderar a plasticidade e a relatividade dos componentes avaliados, por exemplo, interesse e perseverança, uma vez que se expressam em situações distintas e não podem ser apreendidos por um teste. Por fim, as autoras refutam o projeto por não se adequar à realidade e cultura diversas, sendo extremamente rígido nos critérios.

Além disso, o panorama atinente às avaliações educacionais revela políticas mercantis que reforçam a competitividade entre instituições e a supervalorização dos resultados e indicadores, marginalizando ainda mais as escolas que possuem alguma dificuldade no cumprimento das propostas educacionais ou estigmatizando instituições que, apesar de ofertarem uma educação de qualidade e comprometida com as comunidades, não atendem ao modelo avaliativo. Tornando-se o principal instrumento de verificação do desempenho escolar, as políticas de avaliação passaram a ter caráter regulador e compensatório a partir da década de 1990, principalmente pela incorporação da lógica internacional de preparação para o mercado (SOARES; COLARES, 2020).

Como bem colocam Lemos e Macedo (2019, p. 66-67), “As condições socioemocionais serão sempre circunstanciais, portanto imprevistas e não planejáveis. Assim sendo, nos [sic] preocupa a tentativa de imposição do 'tipo ideal' para um mundo globalizado e unívoco". Lemos e Macedo (2019) colocam em pauta a urgência do mundo capitalizado em formar humanos que atendam sem dificuldades às demandas da economia. Os autores retomam a ideia de que tais programas visam à preparação do sujeito para a vida profissional. O presente, conforme Lemos e Macedo (2019), a vivência do aqui e agora se subordina a um futuro incerto, está à mercê de uma promessa de sucesso que não depende unicamente dos esforços individuais, como o apregoado.

$\mathrm{Na}$ etapa do Ensino Médio, o apelo para a preparação do cidadão para a vida profissional é mais intensa, por demandas sociais e individuais, e desde há muito os governos de todo o mundo têm elaborado programas que atendam a essas demandas. Pereira (2019, p. 23-24) levanta documentos-base e faz uma retrospectiva dos primeiros 
projetos destacados no cenário nacional e internacional de uma Educação para a Carreira, cujos objetivos e proponentes curriculares englobam o desenvolvimento de habilidades muito semelhantes às competências socioemocionais, como "Habilidades em usar e praticar bons hábitos de trabalho; Habilidades em desenvolver e empregar um conjunto de valores de trabalho pessoalmente significativos que motivem os indivíduos a querer trabalhar; Habilidades em humanizar o local de trabalho", dentre outras. Nesse levante, o autor faz críticas a alguns modelos de projetos, principalmente por valorizarem estratégias individuais de sobrevivência em um mercado competitivo, hostil e individualista. Pereira (2019), assim como outros autores já citados, deflagra sua palavra contra currículos que se abstêm da discussão sobre desigualdades sociais, preconceitos e barreiras de ordem material que influenciam a performance do indivíduo no mercado de trabalho.

Todos esses aspectos, presentes e ausentes nos programas educacionais, são originários de uma concepção de humano e de educação que alicerçam os currículos. Portanto, estudar tais concepções é passo primordial para compreender que fins objetivam tais programas e quais suas possíveis consequências.

Se, de maneira ampla, o processo educacional é processo de humanização do indivíduo (MIRANDA; RESENDE, 2005), então temos que reconhecer, através das palavras de Freire (2006, p. 33), que "[...] o trabalho humanizante não poderá ser outro senão o trabalho da desmitificação". Desmistificar é desvelar e conhecer a realidade e os processos que nela operam; no caso da educação socioemocional, intrinsecamente relacionada a outros conhecimentos. É apreender as influências e implicações das emoções em nosso desenvolvimento e em nossa subjetividade.

De acordo com Wallon (1977), a emoção é o elo entre o orgânico e o social, e esse elo não sofre rupturas, ainda que haja intelectualização do sujeito. $O$ autor considera as emoções como instrumento de sociabilidade, forma primitiva de comunhão que medeia e introduz o indivíduo no mundo humano e o vincula ao mundo físico.

Assim como Wallon (1977), outros tantos pesquisadores se dedicaram ao estudo e desenvolvimento de teorias em torno das emoções, sendo que aquele muito colaborou com a discussão sobre a relação afetividade-educação. Nas últimas décadas, esses conteúdos ganharam destaque por diversos motivos, e o Plano Nacional de Educação previa o ensino das habilidades socioemocionais. Agora, com a BNCC, a exigência de 
ações direcionadas para uma educação que abranja as competências sociais e emocionais tornou-se realidade, tanto para o setor público quanto para o privado.

Pouco se discute, no entanto, de que maneira esse termo é abordado no documento oficial e quais concepções de emoção são trazidas no texto ao considerar a emoção como uma habilidade. Ora, se a BNCC norteia a formulação dos currículos, é preciso compreender quais são suas bases e que direcionamentos oferece para 0 desafio de uma educação socioemocional na escola. Se admite a relevância do assunto, é pertinente um estudo direcionado a cada etapa do ensino, uma vez que apresenta públicos em fases distintas do desenvolvimento e em contextos com demandas sociais e emocionais também distintas.

Em vista do exposto, a pesquisa em questão teve por objetivo investigar a concepção de habilidades socioemocionais trazida pelo documento BNCC referente à etapa do Ensino Médio e, assim, contribuir teoricamente com a discussão sobre a abordagem da educação socioemocional nos currículos escolares. Pretendeu-se investigar o direcionamento dado pela BNCC ao tema das habilidades socioemocionais; verificar quais bases epistemológicas sustentam a ideia de habilidades socioemocionais, bem como examinar em que áreas do conhecimento essas habilidades são requeridas. Concomitantemente se aprofundou o estudo sobre o papel da emoção no desenvolvimento humano, principalmente na teoria de Henri Wallon.

Durante a pesquisa, houve acréscimo de materiais analisados a fim de ampliar o entendimento e a visão de como a ideia de habilidades socioemocionais comparece nos programas oferecidos às escolas. Foram analisados três materiais didáticos oferecidos por editoras brasileiras para o público de Ensino Médio.

Problematiza-se, neste trabalho, a ideia de habilidades socioemocionais como temática curricular, e não como dimensão constitutiva do humano que perpassa por todos os ambientes e momentos das instituições educacionais. Se, por um lado, defende-se a compreensão das emoções como inerentes ao educando e fundamentais para seu desenvolvimento, há a tendência de trazê-las deslocadas da realidade do sujeito e como instrumento para servir ao sistema social de trabalho. Essas constatações foram realizadas na análise de materiais destinados ao Ensino Médio.

Educ. Form., Fortaleza, v. 6, n. 2, e4406, maio/ago. 2021 


\section{Metodologia}

A pesquisa teve caráter documental, uma vez que investigou materiais que até então não haviam sido analisados, diferindo-se da pesquisa bibliográfica cujo enfoque é análise de diversos autores sobre um tema (SILVA; ALMEIDA; GUINDANI, 2009). Conforme Silva, Almeida e Guindani (2009, p. 8), na análise documental considera-se "[...] o contexto histórico no qual foi produzido o documento, o universo sócio-político do autor e daqueles a quem foi destinado", com vistas a obter melhor interpretação do conteúdo produzido e seus objetivos. Essa visão é compatível com a desenvolvida pela psicologia escolar crítica, que, por sua vez, conforme Moreira e Guzzo (2014), tem por traço principal o materialismo histórico-dialético e considera o sujeito como ser constituído e constituinte da realidade concreta; portanto, as características subjetivas só podem ser analisadas mediante a compreensão dos aspectos sociais que as compõe e que por elas também são compostos.

O exame da BNCC começou pelo estudo das competências gerais da Educação Básica, passando progressivamente pelas áreas do conhecimento, para então compreender e identificar em que níveis e como são abordadas as questões referentes à emoção, mais especificamente no Ensino Médio. Para tanto, foram feitas leituras sucessivas da introdução, onde estão contidos os marcos legais que embasam a BNCC e os fundamentos pedagógicos, e do pacto interfederativo. Logo após, houve o estudo da estrutura do documento a fim de melhor conhecer como comparece a ideia de habilidades socioemocionais. Foi realizada uma busca por termos visando localizar temas correlatos às habilidades socioemocionais, para então identificar os conteúdos ou momentos aos quais estão relacionados.

Como o presente trabalho está vinculado à pesquisa "A emoção na escola: um estudo sobre como a temática da afetividade tem comparecido nas escolas de Educação Básica", foram analisados materiais de editoras brasileiras direcionados ao público do Ensino Médio. Dentre os materiais selecionados, três são destinados ao Ensino Médio, cujas propostas são trabalhar as habilidades socioemocionais, o planejamento de vida e a preparação para o mundo do trabalho.

Durante a análise, as informações foram divididas em dados de identificação e dados de conteúdo, sendo os seguintes: título do material; autor; editora; ano/etapa da 
educação básica a que se destina; ano de publicação; concepção de educação; concepção de indivíduo/ideia de responsabilidade individual; concepção de emoção e de habilidades socioemocionais; concepção de projeto de vida; concepção de felicidade; o que se espera do professor; o que se espera do aluno; literatura/músicas/filmes citados; ideia de individualismo $\mathrm{x}$ universalidade/pertencimento; uso de imperativos $\mathrm{x}$ encaminhamentos para a reflexão; o material parece possibilitar emancipação do pensamento (autonomia) ou padronização e reprodução de ideias?; referências bibliográficas relacionadas à psicologia; outros comentários.

Concomitantemente foram realizados estudos teóricos/bibliográficos das obras fundamentais de Wallon sobre emoção e educação, embasando a investigação e contribuindo com as discussões em grupo e com os orientadores.

\section{Resultados e discussão}

A BNCC tem suas raízes fixadas na Constituição Nacional de 1988, que prevê, no artigo 210, a existência de conteúdos mínimos e obrigatórios, os quais asseguram a formação escolar básica dos brasileiros. Em 1996, foi aprovada a Lei de Diretrizes e Bases da Educação Nacional (LDBEN), seguida da consolidação dos Parâmetros Curriculares Nacionais, a partir de 1997, mas foi somente no começo de 2010, na Conferência Nacional de Educação (Conae), com a presença de especialistas para debater a Educação Básica, que se produziu um documento expondo abertamente sobre a necessidade da BNCC como parte de um Plano Nacional de Educação (PNE).

Em junho de 2014, o PNE foi regulamentado pela Lei oㅜ 13.005, com vigência de dez anos; dentre as metas traçadas, encontram-se aquelas referentes à BNCC. Em novembro do mesmo ano, foi realizada a $2^{2}$ Conae, que teve por resultado importante mobilização para a construção da BNCC. Em dezembro de 2015, as escolas de todo o Brasil se organizaram para discutir o documento preliminar da BNCC.

No segundo semestre de 2016, aconteceram 27 Seminários Estaduais com professores, gestores e especialistas para debater a segunda versão da BNCC; em regime colaborativo, a terceira versão foi tomando forma. À medida que as preliminares foram disponibilizadas, os profissionais da educação criaram comitês de debate e 
sugeriram melhorias através de formulários on-line, até que as últimas versões das três etapas da Educação Básica fossem homologadas.

Concomitante aos esforços dos educadores e especialistas para a concretização da Base, interesses comerciais se fizeram presentes, afinal a população em idade escolar é de aproximadamente 45 milhões (IBGE, 2010) e movimenta um mercado nacional e internacional de editoras, de cursos de formação para professores, de informatização dos ambientes, etc. Macedo (2018) cita exemplos de consultorias municipais para a formulação dos currículos realizadas por empresas privadas e instituições internacionais, as quais, apesar de terem seus resultados contestados inclusive nos próprios cenários, participaram do plano de implementação da Base, orçado em 100 milhões de reais. Ainda que em seu princípio a Base tenha sido pensada e elaborada por atores compromissados com o desenvolvimento social, a autora compreende tais decisões sobre a implementação como perda do caráter público das políticas educacionais, principalmente quando as escolas assimilam o modo de gestão de empresas. A autora afirma ainda que o sucesso apregoado no que tange à qualidade da educação finlandesa perpassa também pela valorização dos profissionais da educação do país, enquanto nós seguimos o caminho de importação dos modelos privados e internacionais (MACEDO, 2018).

Domingues, Toschi e Oliveira (2000, p. 65) afirmam que historicamente o que se tem notado nas políticas brasileiras para a educação é a transposição dos currículos internacionais, os quais afirmam que "[...] os professores têm sido tomados como recursos nas propostas e não como agentes, mesmo quando supostamente ouvidos no processo de elaboração". Essa seria, inclusive, uma das dificuldades de engajamento da própria categoria na concretização das políticas. Um dos aspectos que corrobora para essa denúncia é que a visão de educação pautada no desenvolvimento de competências da BNCC está embasada nas dimensões conceituais trazidas pelo projeto de Educação para a Cidadania Global, organizado pela Organização das Nações Unidas para a Educação, a Ciência e a Cultura (Unesco), sendo também esse o enfoque das avaliações internacionais da Organização para a Cooperação e Desenvolvimento Econômico (OCDE) (BRASIL, 2018). Antes mesmo da BNCC, a LDBEN de 1996, no artigo 9․, faz menção ao termo no intuito de orientar uma educação que não vise ao ensino apenas de conteúdos mínimos, e sim de aprendizagens essenciais. 
O termo "competências" é definido na BNCC como "[...] a mobilização de conhecimentos (conceitos e procedimentos), habilidades (práticas, cognitivas e socioemocionais), atitudes e valores para resolver demandas complexas da vida cotidiana, do pleno exercício da cidadania e do mundo do trabalho" (BRASIL, 2018, p. 8). Nesse sentido, as chamadas habilidades socioemocionais estão incorporadas a competências, e é possível identificá-las com facilidade nas três últimas:

1. Valorizar e utilizar os conhecimentos historicamente construídos sobre o mundo físico, social, cultural e digital para entender e explicar a realidade, continuar aprendendo e colaborar para a construção de uma sociedade justa, democrática e inclusiva. 2. Exercitar a curiosidade intelectual e recorrer à abordagem própria das ciências, incluindo a investigação, a reflexão, a análise crítica, a imaginação e a criatividade, para investigar causas, elaborar e testar hipóteses, formular e resolver problemas e criar soluções (inclusive tecnológicas) com base nos conhecimentos das diferentes áreas. 3. Valorizar e fruir as diversas manifestações artísticas e culturais, das locais às mundiais, e também participar de práticas diversificadas da produção artístico-cultural. 4. Utilizar diferentes linguagens - verbal (oral ou visual-motora, como Libras, e escrita), corporal, visual, sonora e digital -, bem como conhecimentos das linguagens artística, matemática e científica, para se expressar e partilhar informações, experiências, ideias e sentimentos em diferentes contextos e produzir sentidos que levem ao entendimento mútuo. 5. Compreender, utilizar e criar tecnologias digitais de informação e comunicação de forma crítica, significativa, reflexiva e ética nas diversas práticas sociais (incluindo as escolares) para se comunicar, acessar e disseminar informações, produzir conhecimentos, resolver problemas e exercer protagonismo e autoria na vida pessoal e coletiva. 6 . Valorizar a diversidade de saberes e vivências culturais e apropriar-se de conhecimentos e experiências que lhe possibilitem entender as relações próprias do mundo do trabalho e fazer escolhas alinhadas ao exercício da cidadania e ao seu projeto de vida, com liberdade, autonomia, consciência crítica e responsabilidade. 7. Argumentar com base em fatos, dados e informações confiáveis, para formular, negociar e defender ideias, pontos de vista e decisões comuns que respeitem e promovam os direitos humanos, a consciência socioambiental e o consumo responsável em âmbito local, regional e global, com posicionamento ético em relação ao cuidado de si mesmo, dos outros e do planeta. 8. Conhecer-se, apreciar-se e cuidar de sua saúde física e emocional, compreendendo-se na diversidade humana e reconhecendo suas emoções e as dos outros, com autocrítica e capacidade para lidar com elas. 9. Exercitar a empatia, o diálogo, a resolução de conflitos e a cooperação, fazendo-se respeitar e promovendo o respeito ao outro e aos direitos humanos, com acolhimento e valorização da diversidade de indivíduos e de grupos sociais, seus saberes, identidades, culturas e potencialidades, sem preconceitos de qualquer natureza. 10. Agir pessoal e coletivamente com autonomia, responsabilidade, flexibilidade, resiliência e determinação, tomando decisões com base em princípios éticos, democráticos, inclusivos, sustentáveis e solidários. (BRASIL, 2018, p. 10).

Para compreender melhor como as habilidades socioemocionais comparecem na

BNCC para o Ensino Médio, foi realizada inicialmente uma busca por palavras e, em

seguida, a análise sobre os assuntos aos quais estão relacionadas, chegando-se aos

Educ. Form., Fortaleza, v. 6, n. 2, e4406, maio/ago. 2021

DOI: https://doi.org/10.25053/redufor.v6i2.4406

https://revistas.uece.br/index.php/redufor/index 
seguintes resultados: emoção (duas menções), emoções (cinco menções), socioemocionais (duas menções), sentimento (quatro menções), empatia (cinco menções). Eles são usados nos seguintes contextos: definição das competências 2, 6 e 8, definição de BNCC, sobre o campo artístico e literário, na parte de linguagens e suas tecnologias, sobre a Educação Física e na contextualização do Ensino Médio na Educação Básica.

Também é válido mencionar que a palavra "diálogo" é muito utilizada no documento (18 menções) e perpassa por inúmeras habilidades de caráter socioemocional, como a capacidade de apropriação do discurso e de contato com o contraditório e como alternativa às reações violentas.

Essas palavras não aparecem em temas específicos, independentes ou distantes dos conteúdos, ao contrário, encontram-se intrínsecas ao processo de aprendizagem ou como finalidade da ação educativa. Por exemplo, as emoções e a empatia, no trecho a seguir, aparecem como inerentes ao sujeito durante o contato com as diversas manifestações artísticas: "A fruição, alimentada por critérios estéticos baseados em contrastes culturais e históricos, deve ser a base para uma maior compreensão dos efeitos de sentido, de apreciação e de emoção e empatia ou repulsão acarretados pelas obras e textos" (BRASIL, 2018, p. 488).

O Quadro 1 mostra a síntese das categorias analisadas no documento da BNCC para o Ensino Médio e revela em que tópico ou área do conhecimento cada menção ocorre:

Quadro 1 - Síntese das categorias analisadas no documento da BNCC para o Ensino Médio

\begin{tabular}{|c|c|c|}
\hline $\begin{array}{l}\text { Termos } \\
\text { buscados no } \\
\text { documento }\end{array}$ & $\begin{array}{l}\text { Número de } \\
\text { menções }\end{array}$ & Tópico ou área do conhecimento em que aparece \\
\hline Emoção & 2 & $\begin{array}{l}\text { - Linguagens e suas tecnologias no Ensino médio: competências } \\
\text { específicas e habilidades - Competência específica } 6 \text { (p. 488) } \\
\text { - Campo artístico e literário - Parâmetros para a } \\
\text { organização/progressão curricular (p. 514) }\end{array}$ \\
\hline Emoções & 5 & $\begin{array}{l}\text { - Introdução - Competências gerais da Educação Básica (p. 10) } \\
\text { - A área de linguagens e suas tecnologias (p. 475) } \\
\text { - Língua portuguesa - Campo artístico e literário (p. 496) } \\
\text { - Campo artístico e literário (p. 513) } \\
\text { - Campo artístico e literário (p. 514) }\end{array}$ \\
\hline Socioemocionais & 2 & $\begin{array}{l}\text { - Introdução - Definição de competência na BNCC (p. 8) } \\
\text { - Capítulo } 5 \text { - Ensino Médio no contexto da Educação Básica } \\
\text { (p. 464) }\end{array}$ \\
\hline
\end{tabular}

Educ. Form., Fortaleza, v. 6, n. 2, e4406, maio/ago. 2021

DOI: https://doi.org/10.25053/redufor.v6i2.4406

https://revistas.uece.br/index.php/redufor/index 
Quadro 1 - Síntese das categorias analisadas no documento da BNCC para o Ensino Médio

(conclusão)

\begin{tabular}{|c|c|c|}
\hline $\begin{array}{l}\text { Termos } \\
\text { buscados no } \\
\text { documento }\end{array}$ & $\begin{array}{l}\text { Número de } \\
\text { menções }\end{array}$ & Tópico ou área do conhecimento em que aparece \\
\hline Sentimento & 5 & $\begin{array}{l}\text { - Introdução - Competências gerais da Educação básica (p. 9) } \\
\text { - A área de linguagens e suas tecnologias (p. 473) } \\
\text { - Língua portuguesa - Campo artístico e literário (p. 496) } \\
\text { - Língua portuguesa - Campo artístico e literário (p. 514) } \\
\text { - Língua portuguesa - Campo artístico e literário - Parâmetros para } \\
\quad \text { a organização/progressão curricular (p. 514) }\end{array}$ \\
\hline Empatia & 5 & $\begin{array}{l}\text { - Introdução - Competências gerais da Educação Básica (p. 10) } \\
\text { - Competências específicas de linguagens e suas tecnologias para } \\
\text { o Ensino Médio (p. 481) } \\
\text { - Linguagens e suas tecnologias no Ensino Médio: competências } \\
\text { específicas e habilidades - Competência específica } 2 \text { (p. 484) } \\
\text { - Linguagens e suas tecnologias no Ensino Médio: competências } \\
\text { específicas e habilidades - Competência específica } 6 \text { (p. 488) } \\
\text { - Língua portuguesa - Campo artístico e literário (p. } 496)\end{array}$ \\
\hline Diálogo & 18 & $\begin{array}{l}\text { - } 1 \text { menção: Introdução - Competências gerais da Educação } \\
\text { básica (p.9) } \\
\text { - } 3 \text { menções: Capítulo } 5 \text { - Ensino Médio no contexto da Educação } \\
\text { Básica (p. 463, 465, 468) } \\
\text { - } 1 \text { menção: Linguagens e suas tecnologias (p. 475) } \\
\text { - } 1 \text { menção: Competências específicas de linguagens e suas } \\
\text { tecnologias para o Ensino Médio (p. 481) } \\
\text { - } 3 \text { menções: Linguagens e suas tecnologias - Competência } \\
\text { específica } 2 \text { (p. } 484) \\
\text { - } 2 \text { menções: Linguagens e suas tecnologias - Campo artístico e } \\
\text { literário (p. } 513 \text { ) } \\
\text { - } 2 \text { menções: Linguagens e suas tecnologias - Práticas do campo } \\
\text { artístico e literário (p. } 515-516) \\
\text { - } 4 \text { menções: Ciências da natureza e suas tecnologias - } \\
\text { Competência específica } 3 \text { (p. 544; } 548) \\
\text { - } 1 \text { menção: Ciências humanas sociais aplicadas - Competência } \\
\text { específica } 6 \text { (p. } 565)\end{array}$ \\
\hline Trabalho & 80 & $\begin{array}{l}\text { Foram focados os trechos em que aparecia explicitamente a relação } \\
\text { entre a proposta da Base e a formação para o trabalho, } \\
\text { principalmente contidos na Introdução }\end{array}$ \\
\hline
\end{tabular}

Fonte: Dados da pesquisa coletados na BNCC (BRASIL, 2018).

Não há no documento uma definição ou referência teórica de emoção, habilidades sociais e suas características, mas há, como descrito acima, o momento em que se espera desenvolvê-las ou que elas compareçam no educando. A BNCC também não se propõe a demonstrar ou guiar o "como fazer", pois é um documento de caráter norteador para a elaboração dos currículos, o que permite às instituições, em suas singularidades e contextos sociais, o desenvolvimento de ações pedagógicas particulares.

Desse modo, ficam a cargo das equipes educativas a adoção de materiais ou a formulação dos próprios programas, a admissão dos referenciais teóricos que melhor 
Ihes convier e a interpretação sobre os fins dessas competências. Se, por um lado, essa flexibilidade permite a diversidade, também pode acarretar 0 desenvolvimento de projetos semelhantes aos criticados por Patto (2000) e Smolka et al. (2015), em que as expressões socioemocionais são tomadas como instrumento para o sucesso econômico e promoção de uma sociedade individualista.

Apesar de a BNCC abordar as competências de maneira interdisciplinar, ressaltando que na aprendizagem de conhecimentos específicos existem desdobramentos no campo socioemocional, o que tem se notado, pelo menos nas instituições goianienses, é que as escolas vislumbram programas específicos para as competências socioemocionais.

$\mathrm{Na}$ análise de três materiais de educação socioemocional para o Ensino Médio, cujos tópicos investigados encontram-se na parte de metodologia, ficou evidente o direcionamento para o mundo do trabalho e planejamento de vida. Ainda que os materiais sistematizem atividades reflexivas sobre escolhas, consequências, desejos, histórias de vida, é gritante a ausência de um pensamento crítico acerca das condições sociais que os determinam, inclusive que permitem o acesso a uma formação. Dentre os aspectos analisados, chamam a atenção a ideia de responsabilidade individual, a ideia de individualismo $x$ universalidade/pertencimento e o que se espera do professor.

De maneira geral, percebe-se a defesa da meritocracia. Em um dos materiais, utilizam-se as ideias de Epíteto ${ }^{1}$ e Sartre ${ }^{2}$ associadas à ideia de responsabilidade pessoal, sem apresentar contrapontos, o que reforça a concepção de que o esforço é suficiente para alcançar qualquer objetivo, como também considera que há liberdade para tomada de qualquer decisão. Sobre individualismo e universalidade, não é raro encontrar conceitos de parceria e amizade associados a ganhos pessoais, como, por exemplo, a relação em que ambos se beneficiam e a ajuda para organizar e estruturar projetos. Os temas que versam sobre as relações sociais têm em vista um ideal, distanciando-se de questões cotidianas e concretas da vida do sujeito.

\footnotetext{
1 Filósofo grego pertencente à Escola Estoica, viveu entre 55 d.C. e 135 d.C. Suas ideias centrais versam sobre a conquista da felicidade pela virtude e pela razão. Compreende também que os esforços humanos devem ser dirigidos para a mudança daquilo que pode ser mudado, sendo que aquilo que não está sob seu poder e, portanto, não pode sofrer modificações deve ser aceito.

2 Filósofo francês, um dos principais representantes do Existencialismo, viveu entre 1905 e 1980. Dentre as diversas temáticas abordadas em suas obras, ficaram mais conhecidas aquelas que dizem respeito à liberdade. Para Sartre, o ser humano está inevitavelmente condenado à liberdade de escolher, ainda que as circunstâncias exerçam importante papel nesse processo.
}

Educ. Form., Fortaleza, v. 6, n. 2, e4406, maio/ago. 2021

DOI: https://doi.org/10.25053/redufor.v6i2.4406

https://revistas.uece.br/index.php/redufor/index 
Na BNCC, a menção à preparação para o mundo do trabalho é feita logo na Introdução e reiterada na competência 6, assim como no tópico sobre os marcos legais. Ora a qualificação é mencionada como direito, ora é mencionada como aspecto a ser desenvolvido e que depende do educando. Em seu bojo, o documento traz a certeza sobre as instabilidades que caracterizam o novo modelo de produção e suas implicações na formação escolar, desse modo enfatiza que o ensino guiado pelo desenvolvimento de competências seria o ideal para a atual conjuntura. As competências são descritas como comportamentos gerais que se desdobram em habilidades, que, por sua vez, são mencionadas em termos de comportamentos desejados, aonde chegar, e não necessariamente sobre o percurso ou sobre o contexto de onde se parte. Ainda que a BNCC afirme categoricamente sobre a importância de se considerar a realidade social dos educandos e os têm como sujeitos históricos, na aplicação, como apresentado pelos materiais analisados, o ensino por competências tende a responsabilizar o discente por sua capacidade de "aprender a aprender", seguindo o viés de autossuficiência dos alunos marcada pela tônica necessária de adaptação ao mercado.

Neste sentido, Silva e Guedes (2018, p. 106) afirmam: “[...] estão também colocados meandros dos mecanismos de recuo da função precípua da escola de propiciar acesso, ensinar e transmitir os conhecimentos socialmente produzidos e sistematizados nas diversas áreas da formação humana". Assim, os educandos seriam os principais agentes na transformação de potenciais em atitudes concretas, e a escola seria a catalisadora da capacidade de sempre aprender e adaptar.

Encontramos na Base a seguinte afirmação:

[...] assegurar aos estudantes uma formação que, em sintonia com seus percursos e histórias, faculte-lhes definir seus projetos de vida, tanto no que diz respeito ao estudo e ao trabalho como também no que concerne às escolhas de estilos de vida saudáveis, sustentáveis e éticos. (BRASIL, 2018, p. 263).

Assegurando o desenvolvimento dessas capacidades, nomeadas como competências, a escola estaria cumprindo com a sua função de preparar o indivíduo para escolher, perseverar, analisar e arcar com as consequências dos caminhos traçados, o que, pelo olhar de Silva e Guedes (2018), seria de muito proveito para uma formação crítica e autônoma. No entanto, considerando a escola como espaço de mediação para a formação de trabalhadores e tendo-se consciência dos múltiplos 
interesses do capital, não podemos inocentemente afirmar que o protagonismo juvenil objetiva beneficiar exclusivamente os educandos. Diga-se de passagem que, tendo em vista um mercado extremamente competitivo, instável, com leis trabalhistas precarizadas, a própria educação escolar não é capaz de garantir uma formação que assegure emprego, portanto a ideia de formar trabalhadores que arquem, sem questionar, com as mazelas desse cenário é viável economicamente.

Ademais, mesmo os programas de profissionalização aliados ao Ensino Médio, cujo fim volta-se unicamente à preparação do estudante para o trabalho, encontram inúmeras dificuldades para a apresentação de resultados satisfatórios, desde o financiamento até a preparação dos profissionais, sem mencionar as especificidades das condições de ensino-aprendizagem de cada região (SANTOS; SILVA, F.; SILVA, L., 2019). Esses fatos colocam em dúvida a esperança de uma geração com maiores chances de empregabilidade devido à formação por competências, o que parece indicar maior resistência e resignação frente às condições não muito auspiciosas.

No que tange às expectativas sobre a figura dos professores, em um dos materiais é nítida a cobrança para que o educador seja exemplo em todos os aspectos: empático, feliz, conhecedor de si mesmo, gerente das emoções, muitas vezes conselheiro, disposto e empreendedor, a fim de contagiar seus alunos. Isso implica uma cobrança para além da mediação e organização do conteúdo.

Wallon (1979) defende que haja uma formação psicológica do professor, isto é, que os educadores possuam os conhecimentos básicos de desenvolvimento e aprendizagem dos educandos. Não obstante, o autor trata o professor como sujeito composto por limitações e potenciais, por isso em constante formação. Exigir que o docente seja o modelo perfeito é, sem dúvida, desconsiderar sua humanidade.

É interessante notar a tendência em transformar as habilidades socioemocionais em um conjunto de temáticas específicas de uma disciplina. Esse tipo de metodologia permite inúmeras vantagens, como espaço e tempo para pensar e trabalhar assuntos pertinentes às emoções e vivências dos alunos. Entretanto, pode acentuar a ideia do sujeito fragmentado em cognição e emoção, já que a própria escola divide as matérias conteudistas da disciplina que aborda as competências socioemocionais, como se na aula de conhecimentos científicos não coubessem as expressões da afetividade. 
Há que se pensar também que, como disciplina, as habilidades socioemocionais podem estar sujeitas à avaliação e, a depender da estrutura e finalidade, podem submeter os alunos ao engodo da metrificação e mensuração das características emocionais, como explorado por Smolka et al. (2015). Mais do que isso, sob a pressão de um mundo que cobra resultados visíveis e comparativos, esses dados podem servir como enunciação do educando-modelo, cujo sucesso escolar e profissional são devidos exclusivamente às características desejáveis e à capacidade de reprimir características indesejáveis, ignorando as idiossincrasias, omitindo fatores sociais, culturais e econômicos por trás desse sucesso, como exposto por Patto (2000).

Outro ponto em pauta é a oferta de materiais prontos. Se, por um lado, equipam educadores com o conhecimento mínimo sobre as temáticas e os norteiam quanto às atividades, por outro podem tirar a autonomia dos professores de abordar assuntos que emergem no contexto específico da escola. Muitos materiais vêm divididos em aulas e possuem uma sequência interdependente entre os conteúdos. Assim, no afã de cumprir cronograma e calendário, corre-se o risco de priorizar o material em detrimento das necessidades da turma, perdendo a oportunidade de elaborar projetos autênticos e mais significativos para os alunos. Sob outro ponto de vista, no entanto, os materiais prontos não sobrecarregam os professores da Educação Básica, que, de maneira geral, cumprem carga horária extensa de trabalho.

\section{Considerações finais}

A proposta da BNCC de guiar o ensino escolar em vista ao desenvolvimento de competências é reverberação de decisões nacionais e internacionais, explícitas em documentos como a LDBEN e produzidos pela Unesco, que traçaram objetivos comuns entre países para a educação do novo milênio, os quais configuram, portanto, uma realidade que se concretiza a cada dia. Dentre as dez competências, ganharam destaque as três últimas, que versam sobre habilidades socioemocionais e que foram o foco das investigações do presente trabalho.

Desde há muito discutidas por educadores e psicólogos, é patente a fachada de programas de educação emocional que, ao proporem a formação de cidadãos mais empáticos e felizes, reforçam a cultura individualista pautada na ideia de sucesso 
financeiro. Ao serem investigadas as bases nas quais se apoiam tais programas, encontram-se lacunas teóricas que por vezes velam os aspectos histórico-culturais que constituem o sujeito, a fim de promover uma ideologia meritocrática e manter o status quo de uma sociedade produtora de desigualdade e adoecimento.

É legítima a urgência e pertinência de currículos que consideram a dimensão afetiva dos educandos e que a flexibilidade da BNCC - explicitada inclusive pela não definição de habilidades socioemocionais - permite a produção de projetos plurais, diversos e ricos, assim como a nação brasileira. Conquanto também é imprescindível o acompanhamento dos programas oferecidos e desenvolvidos no campo da educação socioemocional, atentando-se aos aspectos pertinentes à formação dos educadores e exigências que recaem sobre eles, aspectos relativos à rigidez de materiais oferecidos às escolas e relativos à ausência da abordagem sócio-histórica, que desvenda inúmeros componentes na constituição do indivíduo e da sociedade.

O olhar crítico assegura que sejam expostas as finalidades da educação e os caminhos a serem tomados para o alcance de um ensino democrático, que forme cidadãos autônomos e conscientes, para que se tornem sujeitos ativos na manutenção e transformação da sociedade.

\section{Referências}

BRASIL. Base Nacional Comum Curricular: documento de caráter mandatório que orienta a formulação dos currículos escolares. Brasília, DF: Ministério da Educação, 2018.

BRASIL. Lei de Diretrizes e Bases da Educação Nacional: Lei no 9.394, de 20 de dezembro de 1996, que estabelece as Diretrizes e Bases da Educação Nacional. 10. ed. Brasília, DF: Câmara dos Deputados, 2014.

BRASIL. Lei no 13.005, de 25 junho de 2014. Aprova o Plano Nacional de Educação PNE e dá outras providências. Diário Oficial [da] República Federativa do Brasil, Poder Executivo, Brasília, DF, 26 jun. 2014.

BRASIL. Lei no 13.415, de 16 de fevereiro de 2017. Altera as Leis nos 9.394, de 20 de dezembro de 1996, que estabelece as Diretrizes e Bases da Educação Nacional, e 11.494, de 20 de junho 2007, que regulamenta o Fundo de Manutenção e

Desenvolvimento da Educação Básica e de Valorização dos Profissionais da Educação, a Consolidação das Leis do Trabalho - CLT, aprovada pelo Decreto-Lei no 5.452, de 1은 de maio de 1943, e o Decreto-Lei № 236, de 28 de fevereiro de 1967; revoga a Lei no 
11.161, de 5 de agosto de 2005; e institui a Política de Fomento à Implementação de Escolas de Ensino Médio em Tempo Integral. Diário Oficial [da] República Federativa do Brasil, Poder Executivo, Brasília, DF, 17 fev. 2017.

BRASIL. Novo Ensino Médio - perguntas e respostas. Disponível em: http://portal.mec.gov.br/component/content/article?id=40361. Acesso em: 14 jan. 2021.

DA MOTTA, V. C.; FRIGOTTO, G. Por que a urgência da reforma do ensino médio? Medida Provisória oㅡ 746/2016 (Lei oㅜ13.415/2017). Educação \& Sociedade, Campinas, v. 38, n. 139, p. 355-372, 2017. Disponível em: https://www.scielo.br/pdf/es/v38n139/16784626-es-38-139-00355. Acesso em: 18 jan. 2021.

DOMINGUES, J. J.; TOSCHI, N. S.; OLIVEIRA, J. F. A reforma do Ensino Médio: a nova formulação curricular e a realidade da escola pública. Educação \& Sociedade, Campinas, v. 21, n. 70, p. 63-79, 2000. Disponível em: https://www.scielo.br/scielo.php?pid=s0101-

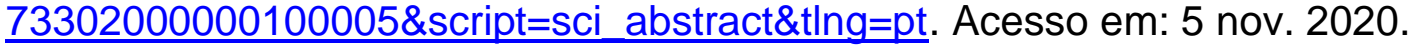

FREIRE, J. S. E. A concepção de competência e a formação da subjetividade do trabalhador. Revista Inter Ação, Goiânia, v. 34, n. 2, p. 307-332, 2009. Disponível em: https://www.revistas.ufg.br/interacao/article/view/8499. Acesso em: 5 nov. 2020.

FREIRE, P. Conscientização, teoria e prática da liberdade. 3. ed. São Paulo: Centauro, 2006.

IAS. Competências socioemocionais: material para discussão. Rio de Janeiro: IAS, 2014.

IBGE. Censo 2010. Rio de Janeiro: IBGE, 2010. Disponível em: https://censo2010.ibge.gov.br/. Acesso em: 18 jan. 2021.

LEITE, S. A. Afetividade nas práticas pedagógicas. Temas em Psicologia, Ribeirão Preto, v. 20, n. 2, p. 355-368, 2012. Disponível em: https://www.redalyc.org/pdf/5137/513751440006.pdf. Acesso em: 5 nov. 2020.

LEMOS, G. A. R.; MACEDO, E. A incalibrável competência socioemocional. Linhas Críticas, Brasília, DF, v. 25, p. 57-73, 2019. Disponível em: https://periodicos.unb.br/index.php/linhascriticas/article/view/24582. Acesso em: 5 nov. 2020.

MACEDO, E. "A base é a base". E o currículo o que é? In: AGUIAR, M. A. S.; DOURADO, L. F. (org.). A BNCC na contramão do PNE 2014-2024: avaliação e perspectivas. Recife: Anpae, 2018. p. 28-33.

MIRANDA, M. G.; RESENDE, A. C. A. A Psicologia da Educação na perspectiva da relação teoria e prática: uma conciliação possível. In: ANPED-GT-20-PSICOLOGIA DA EDUCAÇÃO, 20., 2005, Caxambu. Anais [...]. Caxambu: Anped, 2005. 
MOREIRA, A. P. G.; GUZZO, R. S. L. O psicólogo na escola: um trabalho invisível?. Gerais: Revista Interinstitucional de Psicologia, Uberlândia, v. 7, n. 1, p. 42-52, 2014. Disponível em: http://pepsic.bvsalud.org/scielo.php?script=sci arttext\&pid=S198382202014000100005. Acesso em: 18 jan. 2021.

PATTO, M. H. S. Mutações do cativeiro. In: PATTO, M. H. S. Mutações do cativeiro: escritos de psicologia e política. São Paulo: USP, 2000. p. 157-186.

PEREIRA, O. C. N. A construção do projeto de vida no Programa Ensino Integral (PEI): uma análise na perspectiva da orientação profissional. 2019. $134 \mathrm{f}$. Tese (Doutorado em Psicologia Social) - Programa de Pós-Graduação em Psicologia Social, Universidade de São Paulo, São Paulo, 2019.

RAMOS, M. N. A educação profissional pela pedagogia das competências e a superfície dos documentos oficiais. Educação \& Sociedade, Campinas, v. 23, n. 80, p. 401-422, 2002. Disponível em: https://www.scielo.br/pdf/es/v23n80/12939.pdf. Acesso em: 18 jan. 2021.

SANTOS, J. M.; SILVA, F.; SILVA, L. Política de educação profissional: o programa Brasil profissionalizado no contexto escolar. Educação \& Formação, Fortaleza, v. 5, n. 1, p. 172-194, 2019. Disponível em: https://revistas.uece.br/index.php/redufor/article/view/1801. Acesso em: 18 jan. 2021.

SMOLKA, A. I. B. et al. O problema da avaliação das habilidades socioemocionais como política pública: explicitando controvérsias e argumentos. Educação \& Sociedade, Campinas, v. 36, n. 130, p. 219-242, 2015. Disponível em: https://www.scielo.br/scielo.php?pid=s0101-73302015000100219\&script=sci arttext. Acesso em: 5 nov. 2020.

SILVA, J. R. S.; ALMEIDA, C. D.; GUINDANI, J. F. Pesquisa documental: pistas teóricas e metodológicas. Revista Brasileira de História \& Ciências Sociais, Santa Vitória do Palmar, v. 1, n. 1, p. 1-15, 2009. Disponível em: https://periodicos.furg.br/rbhcs/article/view/10351. Acesso em: 10 jan. 2021.

SILVA, M. M.; GUEDES, T. Formação dos trabalhadores para o capital: uma análise de projetos pedagógicos de cursos técnicos subsequentes do IFSC, campus

Florianópolis. Educação \& Formação, Fortaleza, v. 3, n. 3, p. 102-120, 2018. Disponível em: https://revistas.uece.br/index.php/redufor/article/view/182. Acesso em: 19 jan. 2020.

SOARES, L. V.; COLARES, M. L. I. S. Avaliação educacional ou política de resultados?. Educação \& Formação, Fortaleza, v. 5, n. 3, e2951, 2020. Disponível em: https://revistas.uece.br/index.php/redufor/article/view/2951. Acesso em: 18 jan. 2021.

WALLON, H. O orgânico e o social no homem. In: MERANI, A. L. (org.). Psicologia e pedagogia: as idéias pedagógicas de Henri Wallon. Lisboa: Notícias, 1977. p. 285-295.

WALLON, H. A formação psicológica dos mestres. In: WALLON, H. Psicologia e educação da criança. Lisboa: Vega, 1979. p. 343-354. 
Marina Kurotusch Canettieri, Universidade Federal de Goiás

iDhttps://orcid.org/0000-0002-2757-7526

Graduanda em Psicologia na Universidade Federal de Goiás, campus Goiânia. Formação acadêmica em bacharelado e licenciatura. Bolsista de Iniciação Científica pelo Conselho Nacional de Desenvolvimento Científico e Tecnológico (CNPq).

Contribuição: Primeira Redação, Investigação, Metodologia

Lattes: http://lattes.cnpq.br/1120476227427164

E-mail: $\underline{\text { aniram.kc@gmail.com }}$

\section{Jordana de Castro Balduino Paranahyba, Universidade Federal de Goiás}

ii Dhttps://orcid.org/0000-0002-8718-8944

Psicóloga pela Pontifícia Universidade Católica de Goiás, com mestrado e doutorado em Educação pela Universidade de Barcelona. Professora associada da área de Psicologia da Educação na Faculdade de Educação da Universidade Federal de Goiás.

Contribuição: Orientadora da pesquisa relatada e da escrita do artigo

Lattes: http://lattes.cnpq.br/1444222161390647

E-mail: jordanabalduino@gmail.com

\section{Soraya Vieira Santos, Universidade Federal de Goiás}

iii Dhttps://orcid.org/0000-0002-1606-2543

Pedagoga, mestra e doutora em Educação pela Universidade Federal de Goiás. Professora adjunta da área de Psicologia da Educação na Faculdade de Educação da Universidade Federal de Goiás.

Contribuição: Coordenadora da pesquisa a qual o artigo está relacionado e orientadora na escrita do projeto que deu origem ao trabalho.

Lattes: http://lattes.cnpq.br/2976689970817238

E-mail: soraya vieira@hotmail.com

Editora responsável: Lia Machado Fiuza Fialho

Pareceristas ad hoc: Maria das Dores Mendes e Marina Dias

\section{Como citar este artigo (ABNT):}

CANETTIERI, Marina Kurotusch; PARANAHYBA, Jordana de Castro Balduino; SANTOS, Soraya Vieira. Habilidades socioemocionais: da BNCC às salas de aula. Educ. Form., Fortaleza, v. 6, n. 2, e4406, 2021. Disponível em:

https://revistas.uece.br/index.php/redufor/article/view/4406

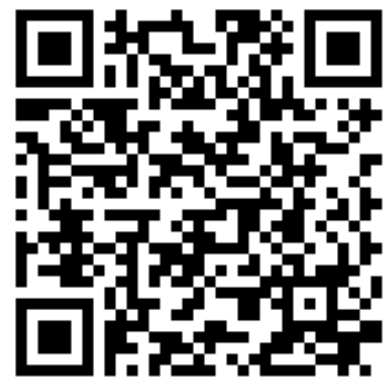

Recebido em 20 de novembro de 2020.

Aceito em 22 de janeiro de 2021.

Publicado em 25 de março de 2021.

Educ. Form., Fortaleza, v. 6, n. 2, e4406, maio/ago. 2021

DOI: https://doi.org/10.25053/redufor.v6i2.4406

https://revistas.uece.br/index.php/redufor/index 